\title{
Editorial
}

\section{The role of change in AJET in 2021: Reflections, bibliometrics, and future plans}

\author{
Linda Corrin \\ Swinburne University of Technology, Australia \\ Gwo-Jen Hwang \\ National Taiwan University of Science and Technology, Taiwan \\ Jason M. Lodge \\ The University of Queensland, Australia \\ Kate Thompson \\ Queensland University of Technology, Australia
}

\begin{abstract}
The end of 2021 marks the first anniversary of the new AJET Lead Editor Team. In this editorial we explore the role of change in the past two years of educational technology in tertiary education, and what this has meant for AJET. We also present the bibliometrics for the year, a summary of what was published in AJET in 2021, and what we have learned as the new lead editor team. We conclude with a look at what is next for AJET as we move into 2022 and a thank you to all the important people who make AJET a success.
\end{abstract}

Keywords: bibliometric data, educational technology, tertiary education

This time last year we started our journey as the new lead editor team of AJET - optimistic and excited about being part of a publication we held in high esteem and had all read, referenced, and contributed to throughout our teaching and research careers. We took up the baton handed over by our predecessors, Professor Michael Henderson, Associate Professor Eva Heinrich, and Professor Petra Redmond who had built the journal up to be the highly respected and impactful publication it is today. It has been an interesting year - a steep learning curve - but ultimately a rewarding experience in helping to make quality educational technology research accessible to the field. In this editorial we will reflect on all that has happened in relation to AJET throughout 2021 - the bibliometrics, what was published, what we have learned, and what is in store for AJET in 2022.

We began the first editorial of 2021 with the statement "2020 was a year of significant change" (Thompson et. al., 2021, p.1). Tertiary education institutions around the world had been forced to make substantial changes to the way they taught and supported students as they grappled with the effects of social distancing and, in some places, extended lockdowns due to COVID-19. Routine approaches to learning and teaching had to be rethought, and many opportunities for innovation and change emerged. The reliance on educational technologies to support these different educational approaches increased substantially, amplifying the importance of publications like AJET to provide evidence-informed ideas for educators and designers transitioning to online and blended learning modes.

2021 has continued to be a year of change, as institutions have taken stock of the results of emergency responses to the delivery of learning and teaching in 2020. Institutional managers and educators have considered decisions such as: which of the newly adopted technology-enabled teaching approaches would stay; how and what parts of the student learning experience would return to the physical classroom; and how to ensure students continue to be supported in their studies, particularly given the high levels of anxiety and uncertainty around the ongoing COVID-19 situation. At the same time, many institutions were forced to restructure in order to find efficiencies in all areas of operation, including learning and teaching. In some cases, this has meant changes to teaching workloads, and prompted many educators to look for ways that technologies can help them to manage and facilitate learning and teaching more efficiently, without diminishing the student experience or the provision of much needed learning support. 
The role of AJET during this time has been to respond to these changes and ensure that the research we publish is relevant and useful to educators in the current climate and into the future. We have spent the first year as lead editors learning the ropes, reviewing processes and systems, and building up our network of Associate Editors and reviewers. The next section includes bibliometric data which demonstrates the number of articles that have been processed this year and the metrics that demonstrate the ongoing impact of AJET.

\section{Bibliometric data for 2021}

Throughout 2021 it was pleasing to see that research into the use of educational technology in tertiary education continued. Sometimes this work referenced approaches that had been newly implemented due to the impact of COVID-19, but also carrying on work started before the pandemic brought about such change. This has enabled us to continue to publish our usual six issues with a total of 67 articles (see Table 1). As at the beginning of December 2021, we also have 12 articles in early release format which demonstrates that we have an increasing number of articles ready in the pipeline for publication in 2022 .

Table 1

AJET Publication Summary

\begin{tabular}{lrrrr}
\hline & 2018 & 2019 & 2020 & 2021 \\
\hline Issues published & 6 & 6 & 6 & 6 \\
Articles published & 57 & 63 & 59 & 67 \\
Editorials published & 6 & 6 & 6 & 6 \\
\hline
\end{tabular}

There has been a steady increase over the last three years in access to full articles in the system. In 2021 a $7 \%$ increase was observed in access to full articles when compared with the 2020 figure. It is useful to note that this percentage increase does not yet include article views throughout December 2021 so the increase will be even larger for the year as a whole.

Table 2

Readership interest in AJET

\begin{tabular}{lrrr}
\hline & 2019 & 2020 & 2021 \\
\hline Access numbers to article landing pages (abstracts) & 323,328 & 416,427 & $170,377^{*}$ \\
Access numbers to full articles & 156,809 & 315,129 & $336,484^{*}$ \\
\hline
\end{tabular}

* These figures are calculated up to $30^{\text {th }}$ November 2021, and do not include accesses in December 2021 .

The number of articles submitted for consideration to AJET in 2021 has also increased in comparison to previous years. To the end of November 2021, 711 articles have been received which is already eight more than the whole of 2020. If we continue to receive articles in December at the same average rate as across the year, we expect to see approximately $10 \%$ increase in overall submissions for 2021 . This is a good indication that authors view AJET as an important venue in which to publish their work. Table 3 below outlines the statistics in relation to submissions and the peer review processes for the past three years.

Table 3

AJET Submission and Review Statistics based on submissions per year

\begin{tabular}{lrrr}
\hline AJET Submissions and Reviews & 2019 & 2020 & $2021^{*}$ \\
\hline Total submissions & 703 & 703 & 711 \\
$\begin{array}{l}\text { Declined at editorial screening (percentage of total } \\
\text { submissions) }\end{array}$ & $565(80 \%)$ & $496(71 \%)$ & $530(75 \%)$ \\
Peer reviewed (percentage of total submissions) & $138(20 \%)$ & $207(29 \%)$ & $171(25 \%)$ \\
$\begin{array}{l}\text { Declined at peer review (percentage of peer reviewed) } \\
\text { Accepted (percentage of peer reviewed) }\end{array}$ & $89(64 \%)$ & $159(77 \%)$ & $121(71 \%)$ \\
$\begin{array}{l}\text { Declined (either at editorial screening or following peer } \\
\text { review, percentage of total submissions) }\end{array}$ & $653(93 \%)$ & $655(93 \%)$ & $651(92 \%)$ \\
\hline
\end{tabular}




\begin{tabular}{llll}
\hline Accepted (percentage of total submissions) & $49(7 \%)$ & $48(7 \%)$ & $50(7 \%)$ \\
\hline
\end{tabular}

* These figures are calculated up to $30^{\text {th }}$ November 2021, and don't include articles processed in December 2021.

In 2021 the AJET Lead Editor Team implemented a new system of editorial screening of submissions to the journal. This was designed to ensure that the process closely aligned to the scope and purpose of the journal while confirming the quality of papers sent through to full review. The process involves two tiers of criteria that an article must meet to assist with the screening process. Tier 1 includes criteria that automatically disqualify an article for inclusion in AJET, including scope (it must be related to the use of technology in tertiary education contexts), formatting, and word count. Once it has been determined that the article meets the Tier 1 criteria, it is then compared to the criteria in Tier 2 which includes quality of writing, reference to recent literature, quality of research design, and contribution to the field. Articles that are questioned in relation to any of the Tier 2 criteria are generally then sent to an Associate Editor with expertise related to the article contents to give an opinion about the screening decision to reject or to send the article through to full peer review. Feedback is provided to any unsuccessful authors in relation to these criteria when they are notified of the outcome of this initial review. The implementation of this new screening process is vital to ensuring that quality research is identified and published, while keeping the workload manageable for our editorial team, copyeditors, and reviewers as the numbers of submissions to AJET continues to rise.

The growth in interest in publishing in AJET may be attributed to the increase in the journal's impact factors as can be seen in Table 4 below. Both the JCR and Scimago impact factors and Scopus' CiteScore rose significantly between 2019 and 2020 and AJET maintained its Q1 rating under the Scimago and Scopus measurements. These results are a credit to the previous AJET Lead Editor Team and something we would like to maintain and improve into the future.

Table 4

AJET Bibliometrics based on calendar year

\begin{tabular}{llccc}
\hline AJET Bibliometrics & & 2018 & 2019 & 2020 \\
\hline JCR & JCR Impact Factor & 1.578 & 1.96 & 3.067 \\
& JCR 5-year Impact Factor & 1.860 & 2.08 & 3.507 \\
& JCR journal ranking in Education & $110 / 243$ & $95 / 263$ & $77 / 265$ \\
& category based on 5-year Impact Factor & $\mathrm{Q} 2$ & $\mathrm{Q} 2$ & $\mathrm{Q} 2$ \\
\hline Scimago & SJR Impact Factor & 0.721 & 0.91 & 1.397 \\
& SJR ranking in Education & $\mathrm{Q} 1$ & $\mathrm{Q} 1$ & $\mathrm{Q} 1$ \\
\hline Google Scholar & H5 index & 28 & 35 & 39 \\
& H5 ranking within Educational & $20 / 20$ & $13 / 20$ & $15 / 20$ \\
& Technology category & & & \\
\hline Scopus & CiteScore & 2.13 & 3.5 & 5.5 \\
& Journal ranking in Education & $155 / 1040$ & $138 / 1254$ & $69 / 1319$ \\
& & $\mathrm{Q} 1$ & $\mathrm{Q} 1$ & $\mathrm{Q} 1$ \\
& SNIP & 1.092 & 1.56 & 1.95 \\
\hline
\end{tabular}

Overall, these bibliometrics show that AJET is an internationally recognised journal in the field of educational technology. The continued increase in impact and quality is a credit to the authors, editorial team, and copyeditors who provide their time and expertise to support the review and publication processes.

\section{What did AJET publish in 2021?}

Articles published in AJET in 2021 included a diversity of pedagogical approaches, technologies, contexts, and research methods. The most downloaded article for the year was the editorial for the third issue which explored the influence that trends have on the ways that educational technologies are adopted and used in tertiary education (Thompson et. al., 2021). This article considered the ways in which trends are identified and the roles that different stakeholders, such as professional societies or journals, play in continuing the conversation in meaningful ways. AJET editorials continue to be among the most popular articles published 
in the journal with the top article for three of this year's issues being the editorial (see Table 3). This indicates that these topics are of interest to our readers and help to contribute to the broader conversation around the direction of educational technology use and research in the field.

Table 3

Top 2021 AJET Articles per Issue by Full Article Downloads to 15/12/2021

\begin{tabular}{|c|c|c|c|}
\hline Issue & Article & Authors & Downloads \\
\hline $\begin{array}{l}\text { Vol } 37, \\
\text { No } 1\end{array}$ & $\begin{array}{l}\text { E-portfolio implementation: Examining learners' } \\
\text { perception of usefulness, self-directed learning process } \\
\text { and value of learning }\end{array}$ & B. K. Song & 1,419 \\
\hline $\begin{array}{l}\text { Vol } 37, \\
\text { No } 2\end{array}$ & The Continuous Pursuit of Smart Learning (Editorial) & $\begin{array}{l}\text { S. K. S. Cheung, F. L. } \\
\text { Wang, L. F. Kwok }\end{array}$ & 750 \\
\hline $\begin{array}{l}\text { Vol } 37, \\
\text { No } 3\end{array}$ & $\begin{array}{l}\text { Trends in education technology in higher education } \\
\text { (Editorial) }\end{array}$ & $\begin{array}{l}\text { K. Thompson, L. Corrin, } \\
\text { G.-J. Hwang, J. M. } \\
\text { Lodge }\end{array}$ & 1,452 \\
\hline $\begin{array}{l}\text { Vol } 37, \\
\text { No } 4\end{array}$ & $\begin{array}{l}\text { Students' preference for the use of gamification in } \\
\text { virtual learning environments }\end{array}$ & $\begin{array}{l}\text { J. K. Acosta-Medina, M. } \\
\text { L. Torres-Barreto, A. F. } \\
\text { Cardenas-Parga }\end{array}$ & 654 \\
\hline $\begin{array}{l}\text { Vol } 37 \\
\text { No } 5\end{array}$ & $\begin{array}{l}\text { Emerging technologies in education for innovative } \\
\text { pedagogies and competency development (Editorial) }\end{array}$ & $\begin{array}{l}\text { A. Abbas, S. Hosseini, J. } \\
\text { L. Nunez, S. Sastre- } \\
\text { Merino }\end{array}$ & 235 \\
\hline
\end{tabular}

In 2021 AJET produced two special issues around key topics in the field. The first special issue (Vol. 37, No. 2) focused on Smart Learning Environments and was overseen by Guest Editors Simon K. S. Cheung and Fu Lee Wang from The Open University of Hong Kong and Lam For Kwok from the City University of Hong Kong. This special issue included articles on a range of smart learning technologies and environments including conversational agents, mobile learning, adaptive platforms, learning analytics, smart classrooms, speech recognition, flipped classroom models, and game-based learning. The final article in the issue presented a review of recent research on smart learning environments to provide insights into the state of the field as well as identify potential areas for future work.

The second special issue for 2021 focused on emerging technologies in education for innovative pedagogies and competency development. In this issue the Guest Editors, Asad Abbas and Samira Hosseini of the Tecnologico de Monterrey (Mexico), and José Luis Martín Núñez and Susana Sastre-Merino of Universidad Politicnica de Madrid (Spain), compiled a range of articles that looked at ways educators are using technologies augmented reality, robotics, student response systems, semantic web, and natural language processing to create innovative learning experiences for students. The issue also included articles that looked at student experiences of emergency online learning in the COVID context, and the readiness of teaching staff to be able to move towards a digital education model.

The general articles and special issue topics provided a broad range of topics, disciplines, methodologies, pedagogies and technologies for our readership in 2021. It is important that the journal represents different contexts and perspectives to ensure that it is making a worthwhile contribution to contemporary discussion and debate within the field.

\section{What other changes happened for AJET in 2021?}

There were a number of other changes that took place for AJET this year. Firstly, the following new Associate Editors were selected to join the AJET editorial team:

- Dr Thomas Chiu, The Chinese University of Hong Kong

- Dr Simon K. S. Cheung, The Open University of Hong Kong

- Dr Feifei Han, Griffith University, Australia

- Dr Kwong Nui Sim, Auckland University of Technology, New Zealand

- Professor Jerry Chih-Yuan Sun, National Chiao Tung University, Taiwan

- A/Professor Lanqin Zheng, Beijing Normal University, Beijing, China

- Assistant Professor, Di Zou, The Education University of Hong Kong 
These new Associate Editors join our existing group, who we acknowledge for their great contribution to overseeing the review processes of AJET:

- A/Professor Thomas Donald Cochrane, The University of Melbourne, Australia

- Dr Christopher E Dann, University of Southern Queensland, Australia

- A/Professor Teresa S Foulger, Arizona State University, United States

- Professor Judi Harris, William and Mary School of Education, United States

- Dr Henk Huijser, Queensland University of Technology, Australia

- A/Professor Matthew Kearney, University of Technology Sydney (UTS), Australia

- Dr Chien-Ching Lee, Singapore Institute of Technology, Singapore

- A/Professor Stephen Marshall, Victoria University of Wellington, New Zealand

- A/Professor Michael Phillips, Monash University, Australia

- Professor Joke Voogt, University of Amsterdam/ Windesheim University of Applied Sciences, Netherlands

- A/Professor Haoran Xie, Lingnan University, Hong Kong

The editors would also like to thank the AJET copyeditors Antonina Petrolito and Kayleen Wood who have worked closely with the Lead Editors to ensure the high standard of final proofs is maintained. This year we have welcomed a new copyeditor to the team, Jen Nichols, to help with the large number of articles coming through the review process.

Throughout 2021 the lead editor team have been reviewing and improving the systems that sit behind the journal's website and online review system. We have begun reviewing the extensive database of users to make sure it is as up to date as possible. In November we upgraded the online platform of the journal to the latest version to expand the functionality available for the publishing process and to address a number of bugs we were experiencing. We have also updated content on the website and are developing a new website design to be released in 2022 .

\section{Looking forward to 2022}

In 2022 we intend to keep improving the journal to ensure it meets the needs of researchers and practitioners in the field. We already have a steady flow of articles going through the review process and will soon release the call for a special issue focusing on the timely topic of achieving optimal and sustainable pedagogical designs for online learning. The international Guest Editors for this issue will include Filia Garivaldis (Monash University), Stephen McKenzie (University of Melbourne), Danah Henriksen (Arizona State University, USA) and Sylvie Studente (Regent's University London, UK).

The editorial team are exploring ways to improve the review and publications processes including the development of a new article template to streamline the review and copyediting processes, systems changes to help prompt reviewers and authors when activities in the review process need to be completed, introduction of the CrossRef platform to ensure the academic integrity of the articles we publish, and a refresh of the AJET website. As mentioned in the editorial for the fourth edition of 2021 (Lodge et. al., 2021) we are also exploring how best to engage with the Open Science and Metascience communities to develop ways for authors to share their data to increase transparency and allow other to replicate studies in other contexts where appropriate. This is an important step in confirming the quality of the research we publish.

Despite the constant change in the tertiary education environment right now, AJET has been able to maintain, and in many ways improve, the quality and output of the journal over the past 12 months. We are indebted to our hardworking Associate Editors and copyeditors, and the hundreds of reviewers who volunteer their time to enable us to identify and publish quality research. We also thank the authors who submit their research for consideration and, if accepted, work alongside the Associate Editors and copyeditors to get their articles to the standard required for publication.

As we reach the end of 2021 and look towards 2022 there are many opportunities for the journal which we will endeavour to capitalise on in the new year. Open access journals like AJET are so important to the 
ongoing development of the field of educational technology. So last, but not least, we also thank our readers, and hope you will continue to engage with the innovative research featured in AJET into the future.

Linda Corrin, Gwo-Jen Hwang, Jason M Lodge, and Kate Thompson

Lead Editors Australasian Journal of Education Technology

\section{References}

Lodge, J. M., Corrin, L., Hwang, G.-J., \& Thompson, K. (2021). Open Science and Educational Technology Research. Australasian Journal of Educational Technology, 37(4), 1-6. https://doi.org/10.14742/ajet.7565

Thompson, K., Corrin, L., Hwang, G.-J., \& Lodge, J. M. (2021). AJET in 2021: Change, bibliometrics and future directions. Australasian Journal of Educational Technology, 37(1), 1-7. https://doi.org/10.14742/ajet.7010

Thompson, K., Corrin, L., Hwang, G.-J., \& Lodge, J. M. (2021). Trends in education technology in higher education. Australasian Journal of Educational Technology, 37(3), 1-4. https://doi.org/10.14742/ajet.7396

Corresponding author: AJET Editors, editors@ ajet.org.au

Copyright: Articles published in the Australasian Journal of Educational Technology (AJET) are available under Creative Commons Attribution Non-Commercial No Derivatives Licence (CC BY-NC-ND 4.0). Authors retain copyright in their work and grant AJET right of first publication under CC BY-NC-ND 4.0.

Please cite as: Corrin, L., Hwang, G-J., \& Lodge, J. M., Thompson, K., (2021). The role of change in AJET in 2021: reflections, bibliometrics and future plans. Australasian Journal of Educational Technology, 37(6), 1-6. https://doi.org/10.14742/ajet.7721 